\title{
Optimizing Inventory Carrying Cost Using Rank Order Clustering Approach for Small and Medium Enterprises (SMES)
}

\author{
D.O.I - 10.51201/Jusst12550 \\ http://doi.org/10.51201/Jusst12550
}

Ganesh B.Narkhede ${ }^{1,2}$, Neela Rajhans ${ }^{3}$

${ }^{1}$ Research Scholar, Department of Production Engineering, College of Engineering, Pune-411011;

${ }^{2}$ Assistant Professor, Departmentof Mechanical Engineering, Vishwakarma Institute of Information Technology, Pune-411048;

${ }^{3}$ Professor, Department of Manufacturing and Industrial Engineering, College of Engineering,

$$
\text { Pune-41101. }
$$

\begin{abstract}
For any company, whether big enterprises or small and medium-sized enterprises (SMEs), inventory is one of the key assets. Therefore, inventory-related decisions directly influence the revenue generated by the firm. This work aims to find a sufficient degree of control over each inventory item and to mitigate the inventory management problems of SMEs. Rank Order Clustering (ROC) algorithm is used in this study for multi-item inventory item aggregation. The proposed framework is tested on a medium-sized gearmanufacturing firm that manufactures 40 different types of planetary and customized gear-boxes. The results demonstrate $47.64 \%$ of cost-saving through the proposed methodology of cluster formation using ROC and quantity discounts. This approach helps to identify different assemblies to aggregate the component requirements and to formulate a particular inventory strategy to minimize inventory carrying costs for each component.
\end{abstract}

Keywords:Small and Medium Enterprises (SMEs), Inventory Management (IM), Rank Order Clustering (ROC) algorithm.

\section{Introduction}

Over the last five decades, the Small and Medium Enterprises (SME) sector has emerged as a highly vibrant and competitive sector of the Indian economy. It can make a major contribution to the country's economic and social growth by creating the greatest job opportunities at a comparatively lower cost of capital, apart from agriculture. SMEs, as ancillary units, are complementary to large industries and this sector has a strong potential to make a significant contribution to the country's growth. In order to meet the demands of domestic and global markets, SMEs are expanding their domain across sectors of the economy, but MSMEs are still lagging in inventory management[1]. The growth in the output and productivity of SMEs was slower than that of large enterprises, based on the World Bank report (2011). Nevertheless, SMEs have become the hub for underutilised and rising labour forces to generate jobs[2].In the manufacturing sector, SMEs implement either job order or batch order production system to fulfill the requirements of their customers[3]. Therefore, the number of components to be handled varies significantly and therefore inventory management becomes very complex. Inventory products that are mismanaged can lead to a major financial problem for the company that results in either excessive inventory or shortage[4].

Small and medium enterprises are small in size, but they contribute significantly to the growth of the economy [5]. India's MSMEs play a crucial role by providing large employment opportunities at relatively lower capital costs than large industries. According to the 73rd round of the National Sample Survey (NSS) conducted by the National Sample Survey Office, the Ministry of Statistics \& Program Implementation, 
there were 633.88 lakh MSMEs in India engaged in various economic activities during the period 201516.[1]. Recently, many researchers have been paying their attention to Inventory management in SMEs. Inventory management helps enterprises to formulate policies to control inventories [6][7][8]. ABC, XYZ, HML \& VED analysis are standard approaches for inventory item classification[9].

In group technology, the Rank Order Clustering algorithm is commonly used[10]. Traditionally, group technology strategy is used to characterize machine groups with an appropriate group layout to make it easier to manufacture components with specific characteristics and similar operations[11]. Iteratively, the ROC algorithm modifies rows and columns, creating a matrix in which both columns and rows are structured in order of decreasing value. The key advantage claimed by ROC over the other strategies lies simply in its ability to effectively cope with the issues of exceptional components and bottleneck machines that often occur in practical problems.

Despite the considerable number of papers addressing inventory management issues in supply chains, many research issues in the area are still neglected. One of the main research gaps in this field concerns the use of simple and effective inventory management technique that SMEs can adopt very easily. This paper addresses this research gap by developing a method to optimize inventory carrying cost by quantity agreegation using rank order clustering approach.

\section{Literature review}

The clustering algorithm known as rank order clustering was first invented by J.R King [12]. Examples of exceptional elements and the case of bottleneck machines were also seen by King. In conclusion, the study presented the ROC algorithm's unique advantages against single clustering algorithms and the method of bond energy. Clustering or group technology aims to characterize unlabeled data sets into object groups [13]. Each category is called a "cluster" which according to specific metrics, consists of similarity to each other and different from other groups [14]. ROC has been implemented in many manufacturing firms to form machines cell formation to react as quickly as possible to meet altering customer demands and to enhance their productivity [15]M.P.Chandrasekharan implemented an upgraded version of the well-known rank order clustering method technique[16].The author introduced the block and slide ROC algorithm and it was intended to significantly reduce the shortcomings, such as the identification of bottleneck machines. Ernst(1990) suggested the Operations Based Groups (ORGs) clustering procedure for inventory systems [17]. Abdul et. al. addressed the use of the analytical hierarchy system for ABC analysis and stressed the multiple criteria inventory item classification on multiple parameters[18].

A classification system for multi-criteria stock items using weighted linear optimization was proposed by Ramanathan (2006)[19]. There are many circumstances where many other factors become significant in deciding the importance of an inventory item, apart from the annual use-value. The researcher also discussed the topic of multi-criteria inventory classification. Bhattacharya (2007) suggested a technique for classifying inventory products using the TOPSIS method that takes into account the distances between the ideal and negative-ideal solutions of each alternative[20]. Many researchershave stressed the use of various inventory classification criteria[21][22]. Few studies provide a thorough comparison between traditional ABC inventory classifications and advanced multiple criteria inventory classification. K.Zalik (2008) brings in k'means algorithm which is a modification of k-means algorithm where pre-assigning the exact number of clusters is not required. Simulated tests were also revealed by the author to validate the efficacy of the proposed algorithm[23].

Wan Lung $\mathrm{Ng}$ (2007) provided a study that transforms an inventory item's multiple criteria measures into a scalar ranking where ranking is based on the measured results using the ABC theory[24]. Peter et al., (2013) identified different mathematical tools for various methods of cluster analysis[25]. The author also studied hierarchical \& non-hierarchical cluster analysis and compared them in detail. A thorough comparison of three inventory classification techniques was proposed by Tomislav Saric et al., (2014): multi-criteria $\mathrm{ABC}$ analysis, neural networks, and cluster analysis (K-means algorithm)[26]. For multi-criteria inventory classification, Mehdi et. Al., (2015) suggested an inventory classification system known as EDAS, wherein positive and negative outcomes, called positive distance from average and negative distance from average, 
are addressed[27]. It is used for testing alternative units for stock-keeping. Raja et.al., (2016) suggested clustering classification of spare parts to carry out inventory classification, actual data consisting of 612 spare parts wereused[28]. As a basis for the classification, 11 variables were identified with the aid of software. Different hierarchical clustering approaches were analyzed by Danijela Pezer (2017), namely single linkage, maximum linkage, weighted linkage, and ward method. Ward's approach was selected to interpret results by the dendrogram, as it helps to define clusters for the classification of inventory objects. The author concluded that hierarchical approaches are successful in determining the optimum number of clusters. The k-algorithm was used to verify the results[29]. E. Balugani et. al., (2018) introduced the method of clustering inventory objects into homogeneous groups to be handled with unique inventory policies by Kalgorithm and ward. The study concluded that there is no need for computationally expensive inventory system management simulations by clustering inventory objects[30].

Literature survey reveals that many researchers have paid their attention in developing inventory policies for large enterprises and these studies lack of simple and cost effective strategies that SMEs can adopt very easilily. In addressing this gap, we propose a novel approach that addressesinventory management issues of SMEs. Our approach applies ROC method in conjuction with quantity discounts to optimize inventory levels to cut the total cost.

\section{Methodology}

In this proposed work, the ROC algorithm is aimed to categorize inventory items for aggregation of inventory items. Rank Order Clustering is traditionally used for grouping of machines but here it is used for cluster formation of inventory items for aggregation of the requirement to optimize inventory carrying cost and ordering cost.

Extensive numerical analysis is conducted on a medium-sized firm that manufactures planetary gearboxes and customized gearboxes to validate the results of the proposed solution. There are multiple components in each gearbox assembly, which range from 14 to 55. Some pieces are made in-house and some of them are bought from suppliers. The range of inventory products to be managed by the company is therefore very broad and difficult, particularly when the demand for gearbox assemblies differs over a period of time. The firm under the organization does not follow any technique to classify inventory items. The procurement process of required goods is carried out when the requirement arises, resulting in shortages or excess inventories. Details of purchased parts for every gearbox assembly are collected to gain control over the procurement procedure. For each gearbox assembly, Table 1 shows the number of components required per assembly.

Table 1. Components required per Gearbox Assembly

\begin{tabular}{|c|c|c|c|c|c|c|c|}
\hline $\begin{array}{c}\text { Assembly } \\
\text { Number }\end{array}$ & $\begin{array}{c}\text { Components } \\
\text { per assembly }\end{array}$ & $\begin{array}{c}\text { Assembly } \\
\text { Number }\end{array}$ & $\begin{array}{c}\text { Components } \\
\text { per assembly }\end{array}$ & $\begin{array}{c}\text { Assembly } \\
\text { Number }\end{array}$ & $\begin{array}{c}\text { Components } \\
\text { per assembly }\end{array}$ & $\begin{array}{c}\text { Assembly } \\
\text { Number }\end{array}$ & $\begin{array}{c}\text { Components } \\
\text { per assembly }\end{array}$ \\
\hline 1095 & 15 & 2130 & 26 & 3095 & 20 & 4095 & 13 \\
\hline 1130 & 24 & 2160 & 25 & 3130 & 28 & 4130 & 25 \\
\hline 1160 & 21 & 2190 & 25 & 3160 & 31 & 4160 & 30 \\
\hline 1190 & 20 & 2230 & 25 & 3190 & 31 & 4190 & 27 \\
\hline 1240 & 23 & 2240 & 32 & 3240 & 43 & 4240 & 27 \\
\hline 1260 & 20 & 2260 & 40 & 3260 & 34 & 4260 & 26 \\
\hline 1280 & 20 & 2280 & 39 & 3280 & 38 & 4280 & 29 \\
\hline 1300 & 14 & 2300 & 29 & 3300 & 41 & 4300 & 34 \\
\hline 1340 & 16 & 2340 & 28 & 3340 & 54 & 4340 & 43 \\
\hline 2095 & 18 & 2380 & 37 & 3380 & 52 & 4380 & 41 \\
\hline
\end{tabular}


ROC has been studied by many manufacturing firms in order to respond as quickly as possible to meet demand variations as well as to boost their productivity. To the best of our knowledge, this is the first time in which ROC is aimed to form clusters of gearbox assemblies in which similar components are being used. The purpose of applying ROC is to aggregate the total required quantity for reducing the total cost by optimizing ordering and inventory carrying cost. The incidence matrix has been formulated by considering the type of gearbox assembly in the column and bought out parts in a row. The incidence matrix for 40 gearboxes and 180 components is constructed by filling the binary values ' 0 'or' 1 . If a specific purchased-out part is needed, binary value ' 1 ' is assigned for specific gearbox assembly, otherwise binary value ' 0 ' is assigned. MS Excel builds the initial incidence matrix consisting of gearbox assemblies in columns and their components in rows. The initial components-assemblies matrix is shown in Fig. 1, but as the whole matrix cannot be shown, only a few components-assemblies matrix is considered to explain the ROC process.

\begin{tabular}{|c|c|c|c|c|c|c|c|c|c|c|c|c|c|c|c|}
\hline $\begin{array}{c}\text { Assembly } \\
\text { Number. } \\
\mathbb{a}\end{array}$ & $\begin{array}{c}\text { Allen } \\
\text { Bolt } \\
\text { 10x30 }\end{array}$ & $\begin{array}{c}\text { Allen } \\
\text { Bolt } \\
10 x 80\end{array}$ & $\begin{array}{c}\text { Allen } \\
\text { Bolt } \\
\text { 10x70 }\end{array}$ & $\begin{array}{c}\text { Allen } \\
\text { Bolt } \\
\text { 10x80 }\end{array}$ & $\begin{array}{l}\text { Ball } \\
\text { Brg. } \\
6212\end{array}$ & $\begin{array}{l}\text { Ball } \\
\text { Brg. } \\
6214\end{array}$ & $\begin{array}{l}\text { Ball } \\
\text { Brg. } \\
6216\end{array}$ & $\begin{array}{l}\text { Ball } \\
\text { Brg. } \\
6217\end{array}$ & $\begin{array}{l}\text { Ball } \\
\text { Brg. } \\
6218\end{array}$ & $\begin{array}{c}\text { Barrel } \\
\text { Nipple } \\
\text { 1/4" } \\
\text { BSP }\end{array}$ & $\begin{array}{c}\text { Breather } \\
\text { Plug } \\
\text { 1/2" } \\
\text { BSP }\end{array}$ & $\begin{array}{c}\text { Breather } \\
\text { Plug } \\
1 / 4^{\prime \prime} \\
\text { BSP }\end{array}$ & $\begin{array}{c}\text { Copper } \\
\text { Washer } \\
\text { M } 8\end{array}$ & $\begin{array}{l}\text { Drain } \\
\text { Plug } \\
1 / 2 " \\
\text { BSP }\end{array}$ & $\begin{array}{c}\text { External } \\
\text { Circlip } \\
\text { A 20 }\end{array}$ \\
\hline 1095 & & & & & & & 1 & & & 1 & & & 1 & & \\
\hline 1130 & 1 & & & 1 & & & & 1 & & 1 & & 1 & & 1 & \\
\hline 1160 & & & & & & & & & & 1 & & & & & \\
\hline 1190 & & & & & & 1 & & & & & & & & & \\
\hline 1240 & & 1 & 1 & & & & & & 1 & & & & 1 & & \\
\hline 1260 & & 1 & 1 & & & & & & & & 1 & & & & \\
\hline 1280 & 1 & & & 1 & & & & & & & & & & & \\
\hline 1300 & 1 & & & & & 1 & & & & 1 & & & & & \\
\hline 1340 & & & & & 1 & & & & & & & & & & \\
\hline 2095 & & & & & & & & & & 1 & & & & & 1 \\
\hline 2130 & & 1 & & & & & & & & & & 1 & 1 & & \\
\hline 2160 & & & & & & & & & & & & 1 & & & \\
\hline 2190 & & & & & & & & & 1 & & & & & & 1 \\
\hline 2230 & 1 & & 1 & & & 1 & & & & & 1 & & & & \\
\hline 2240 & & & 1 & & & & & & & & & & 1 & & \\
\hline
\end{tabular}

Figure1. Initial Components Vs Assemblies matrix

Finally, the ROC algorithm is used on the incidence matrix to get the grouping of gearbox assemblies and bought out parts. This approach is illustrated with a stepwise procedure as given below.

- Step-1 is carried out on the initial matrix, by assigning binary weight to each column. In the column, 180 components are given, so binary values are allocated from $2^{\wedge} 179$ to $2^{\wedge} 0$ from right to left.

- Step-2 is then carried out as per the formula, by computing the decimal equivalent for each row.

- Step-3 The rows are now rearranged with their decimal equivalent values in descending order.

- Step-4 In the next step, binary values ranging from $2^{\wedge} 39$ to $2^{\wedge} 0$ are given to rows from bottom to up as per step-4 of the algorithm.

- Step-5 Each column's decimal equivalent is determined.

- Step-6 The columns are rearranged with their decimal equivalent values in descending order. Since there is a column rearrangement, the second iteration of the algorithm will occur.

Steps 1 to 6 are replicated until there is no rearrangement in either rows or columns. Finally, the algorithm stopped after the third iteration. Finally, after the third iteration, the algorithm stopped. Once the Rank Order Clustering algorithm stops, the next step is to classify final iteration groups or clusters. 
Figure 2 shows the matrix after exchanging selected rows and columns with the application of ROC.

\begin{tabular}{|c|c|c|c|c|c|c|c|c|c|c|c|c|c|c|c|}
\hline $\begin{array}{c}\text { Assembly } \\
\text { No } \\
\mathbb{l}\end{array}$ & $\begin{array}{c}\text { Allen } \\
\text { Bolt } \\
\text { 10x80 }\end{array}$ & $\begin{array}{l}\text { Ball } \\
\text { Brg. } \\
6212\end{array}$ & $\begin{array}{l}\text { Ball } \\
\text { Brg. } \\
6214\end{array}$ & $\begin{array}{c}\text { Allen } \\
\text { Bolt } \\
10 x 80\end{array}$ & $\begin{array}{c}\text { Copper } \\
\text { Washer } \\
\text { M } 8\end{array}$ & $\begin{array}{c}\text { Allen } \\
\text { Bolt } \\
\text { 10x70 }\end{array}$ & $\begin{array}{l}\text { Ball } \\
\text { Brg. } \\
6218\end{array}$ & $\begin{array}{l}\text { Ball } \\
\text { Brg. } \\
6216\end{array}$ & $\begin{array}{c}\text { Allen } \\
\text { Bolt } \\
\text { 10x30 }\end{array}$ & $\begin{array}{c}\text { Breather } \\
\text { Plug } \\
\text { 1/4" } \\
\text { BSP }\end{array}$ & $\begin{array}{c}\text { Drain } \\
\text { Plug } \\
\text { 1/2" } \\
\text { BSP }\end{array}$ & $\begin{array}{l}\text { Ball } \\
\text { Brg. } \\
6217\end{array}$ & $\begin{array}{c}\text { External } \\
\text { Circlip } \\
\text { A } 20\end{array}$ & $\begin{array}{c}\text { Barrel } \\
\text { nipple } \\
\text { 1/4" } \\
\text { BSP }\end{array}$ & $\begin{array}{c}\text { Breather } \\
\text { Plug } \\
\text { 1/2" } \\
\text { BSP }\end{array}$ \\
\hline 1240 & & & & 1 & 1 & 1 & 1 & & & & & & & & \\
\hline 1260 & & & & 1 & & 1 & & & & 1 & & & & & 1 \\
\hline 1095 & 1 & & & & 1 & & & 1 & & & & & & 1 & \\
\hline 2240 & & & 1 & & & 1 & & & & & & & & & \\
\hline 1340 & & 1 & & & & & & & & & & & & & \\
\hline 2095 & & & & & & & & & & & & & & & \\
\hline 2190 & & & & & 1 & & 1 & & & & & & & & \\
\hline 2130 & & & 1 & & & & & & & & & & & & \\
\hline 2160 & 1 & & & & & & & & & & & & & & \\
\hline 1300 & & & & & & & & & 1 & & & & 1 & 1 & \\
\hline 1160 & & & & & & & & & & 1 & & & & 1 & 1 \\
\hline 2230 & & & & 1 & & 1 & & & 1 & & 1 & & & & 1 \\
\hline 1280 & & & & & & & & & 1 & & & & 1 & & \\
\hline 1130 & & & & & & & & & 1 & & & 1 & & 1 & 1 \\
\hline 1190 & & & 1 & & & & & & & & 1 & & & & \\
\hline
\end{tabular}

Figure2. Final Matrix

As shown in fig.2, the final matrix helpsto purchase managers to identify the common components used in various assemblies and aggregate the quantity needed to order in larger amounts rather than more frequently ordering. The major objective is to identify the common components and to aggregate customer's demands.

\section{Results and discussion}

The matrix manipulation results in two different clusters with few outliers for all the 180 components and 40 assemblies, as shown in table 2 .

Table 2. Cluster details

\begin{tabular}{|c|c|c|}
\hline Clusters & $\begin{array}{c}\text { Number of } \\
\text { Components }\end{array}$ & $\begin{array}{c}\text { The number of gear-box } \\
\text { assemblies per group. }\end{array}$ \\
\hline Group 1 & 100 & 24 \\
\hline Group 2 & 31 & 16 \\
\hline Outliers & 43 & - \\
\hline
\end{tabular}

With the final matrix, assemblies 1280, 1300, and 2380 are identified in which Allen Bolt 10x80 is the common component. Their per periodrequirements are summarized in Table 3. 
Table 3. Components required per assembly

\begin{tabular}{|c|c|c|c|}
\hline $\begin{array}{c}\text { Assembly } \\
\text { Numbers } \rightarrow\end{array}$ & $\mathbf{1 2 8 0}$ & $\mathbf{1 3 0 0}$ & $\mathbf{2 3 8 0}$ \\
\hline April & 10 & 24 & 40 \\
\hline May & 0 & 16 & 8 \\
\hline June & 10 & 48 & 16 \\
\hline July & 10 & 0 & 8 \\
\hline August & 10 & 8 & 24 \\
\hline September & 0 & 0 & 16 \\
\hline October & 10 & 16 & 32 \\
\hline November & 0 & 16 & 88 \\
\hline December & 0 & 0 & 40 \\
\hline January & 10 & 32 & 80 \\
\hline February & 0 & 0 & 24 \\
\hline March & 20 & 16 & 16 \\
\hline
\end{tabular}

\subsection{Existing purchase policy}

The purchasing manager applies the lot for lot technique in the current purchase policy and executes separate orders for each assembly in each period. For each product, purchase managers have established more than one supplier, and suppliers offer the same component at differing prices. Therefore, the current order strategy leads to higher costs of ordering and often stock-out conditions. Table 4 presents sample calculations for assembly 1280 .

Table 4. Sample calculation to evaluate the assembly-wise cost

\begin{tabular}{|c|c|c|}
\hline $\begin{array}{c}\text { Present order quantity per } \\
\text { period }\end{array}$ & $\begin{array}{c}\text { Ordering } \\
\text { cost }\end{array}$ & $\begin{array}{c}\text { Procurement } \\
\text { cost }\end{array}$ \\
\hline 10 & 150 & 327 \\
\hline 0 & 0 & 0 \\
\hline 10 & 150 & 327 \\
\hline 10 & 150 & 327 \\
\hline 10 & 150 & 327 \\
\hline 0 & 0 & 0 \\
\hline 10 & 150 & 327 \\
\hline 0 & 0 & 0 \\
\hline 0 & 0 & 0 \\
\hline 10 & 150 & 327 \\
\hline 0 & 0 & 0 \\
\hline 20 & 150 & 653 \\
\hline & Total: & $3664 /-$ \\
\hline
\end{tabular}


Similarly, purchasing the required quantity of Allen Bolt 10x80 for assembly numbers 1300 and 2380 respectively costs Rs. 6950/- and 14907/-. Therefore, the total cost needed for the procurement of the total quantity in the current policy is Rs. 25221/-.

\subsection{Cost saving through the proposed method}

The implementation of the proposed model is demonstrated by the same multi-period, single-item, lotsizing problem in order to find an optimal solution over the entire one-year planning horizon.

- Item Name: Allen Bolt 10x80.

- The supplier-wise price details are shown in Table 5.

Table 5. Supplier-wise price details

\begin{tabular}{|c|c|}
\hline Suppliers of Allen Bolt 10x80 & Price/unit. \\
\hline Om Sai Enterprise & 17.6 \\
\hline Southern Engineers & 25.03 \\
\hline Om Sales Enterprise & 32.67 \\
\hline
\end{tabular}

ROC implementation helps purchase managers to identify the assemblies consisting of Allen Bolt 10x80 and aggregate the quantity required in three assemblies. Table 6 gives the aggregate quantity of Allen Bolt 10x80 per period.

Table 6- Aggregated quantity per period

\begin{tabular}{|c|c|c|c|c|}
\hline $\begin{array}{l}\text { Assembly } \\
\text { Number } \rightarrow\end{array}$ & $\mathbf{1 2 8 0}$ & $\mathbf{1 3 0 0}$ & $\mathbf{2 3 8 0}$ & $\begin{array}{c}\text { Aggregated quantity per } \\
\text { period. }\end{array}$ \\
\hline Apr & 10 & 24 & 40 & 74 \\
\hline May & 0 & 16 & 8 & 24 \\
\hline Jun & 10 & 48 & 16 & 74 \\
\hline Jul & 10 & 0 & 8 & 18 \\
\hline Aug & 10 & 8 & 24 & 42 \\
\hline Sep & 0 & 0 & 16 & 16 \\
\hline Oct & 10 & 16 & 32 & 58 \\
\hline Nov & 0 & 16 & 88 & 104 \\
\hline Dec & 0 & 0 & 40 & 40 \\
\hline Jan & 10 & 32 & 80 & 122 \\
\hline Feb & 0 & 0 & 24 & 24 \\
\hline Mar & 20 & 16 & 16 & 52 \\
\hline
\end{tabular}

Now, instead of ordering three times, procurement managers may order aggregate quantities of three assemblies in a single order. This would help to order the total aggregated quantity at the lowest possible price offered by vendors, resulting in cost advantages, as shown in Table 7. 
Table 7. cost benefits of quantity discounts

\begin{tabular}{|c|c|c|}
\hline $\begin{array}{l}\text { Total quantity to be } \\
\text { ordered }\end{array}$ & Ordering cost & Purchase cost \\
\hline 74 & 150 & 1302.4 \\
\hline 24 & 150 & 422.4 \\
\hline 74 & 150 & 1302.4 \\
\hline 18 & 150 & 316.8 \\
\hline 42 & 150 & 739.2 \\
\hline 16 & 150 & 281.6 \\
\hline 58 & 150 & 1020.8 \\
\hline 104 & 150 & 1830.4 \\
\hline 40 & 150 & 704 \\
\hline 122 & 150 & 2147.2 \\
\hline 24 & 150 & 422.4 \\
\hline 52 & 150 & 915.2 \\
\hline & Total: & 13205 \\
\hline & & \\
\hline &
\end{tabular}

It costs Rs 13205 to buy the same quantity as in the case of the present system after implementing the ROC and quantity discount.To buy the same quantity of Allen Bolt 10x80, this technique will save 47.64 percent of the overall annual cost.To measure the total cost savings per annum, the same method can be extended to the remaining 179 items.

\section{Conclusion}

The knowledge gained from the above numerical analysis showed potential savings of 47.64 percent for multi-period, single-item, lot-sizing inventory management problems. For an increase in the quantity, this percentage would increase. In the current procurement policy, individual orders were placed with no inventory policy to purchase the required quantity of each gear-box assembly.Different assemblies consisting of similar components were identified with the application of ROC.This results in component aggregation, which further led to a significant decrease in inventory and ordering costs. As quantity increases, more quantity discounts may be requested from suppliers.

This concept can be extended to remaining items, to form inventory strategies for SMEs which will help to scale their inventories up or down and for getting more quantity discounts from suppliers.

\section{REFERENCES}

[1] GOI, “Annual Report 2018-19, MSME, GOI,” Minist. Micro, Small Mediu. Enterp. GOI, pp. 16891699, 2019.

[2] D. A. Razak, M. A. Abdullah, and A. Ersoy, "Small Medium Enterprises (SMES) in turkey and Malaysia a comparative discussion on issues and challenges," 15th Kuala Lumpur Int. Bus. Econ. Law Conf. 2018 (KLIBEL 15), vol. na, no. na, pp. 1-12, 2018, [Online]. Available: http://irep.iium.edu.my/63627/.

[3] J. M. Müller, O. Buliga, and K. I. Voigt, "Fortune favors the prepared: How SMEs approach business model innovations in Industry 4.0," Technol. Forecast. Soc. Change, vol. 132, no. January, pp. 2-17, 2018, doi: 10.1016/j.techfore.2017.12.019.

[4] M. Victoire, "Inventory Management Techniques and Its Contribution on Better Management of Manufacturing Companies in RWANDA Case Study: SULFO RWANDA Ltd," Eur. J. Acad. Essays 
ISSN, vol. 2, no. 6online, pp. 49-58, 2015, [Online]. Available: www.euroessays.org.

[5] G. Narkhede and N. Rajhans, "Insights on Supply chain needs and issues in Indian SMEs., " Ind. Eng. J., vol. 12, no. 2, 2019, doi: 10.26488/iej.12.2.1174.

[6] M. Guajardo, M. Rönnqvist, A. M. Halvorsen, and S. I. Kallevik, "Inventory management of spare parts in an energy company,” J. Oper. Res. Soc., vol. 66, no. 2, pp. 331-341, 2015, doi: 10.1057/jors.2014.8.

[7] E. Chinello, Z. N. Lee Herbert-Hansen, and W. Khalid, "Assessment of the impact of inventory optimization drivers in a multi-echelon supply chain: Case of a toy manufacturer," Comput. Ind. Eng., vol. 141, no. January, p. 106232, 2020, doi: 10.1016/j.cie.2019.106232.

[8] H. Al-Momani, O. T. Al Meanazel, E. Kwaldeh, A. Alaween, A. Khasaleh, and A. Qamar, "The efficiency of using a tailored inventory management system in the military aviation industry," Heliyon, vol. 6, no. 7, p. e04424, 2020, doi: 10.1016/j.heliyon.2020.e04424.

[9] R. E. Stanford and W. Martin, "Towards a normative model for inventory cost management in a generalized ABC classification system," J. Oper. Res. Soc., vol. 58, no. 7, pp. 922-928, 2007, doi: 10.1057/palgrave.jors.2602203.

[10] H. M. Shieh and M. Der May, "Solving the capacitated clustering problem with genetic algorithms," J. Chinese Inst. Ind. Eng., vol. 18, no. 3, pp. 1-12, 2001, doi: 10.1080/10170660109509453.

[11] C. H. Cheng, C. H. Goh, and A. Lee, "Solving the generalized machine assignment problem in group technology,” J. Oper. Res. Soc., vol. 47, no. 6, pp. 794-802, 1996, doi: 10.1057/jors.1996.99.

[12] J. R. King, "Machine-component grouping in production flow analysis: An approach using a rank order clustering algorithm," Int. J. Prod. Res., vol. 18, no. 2, pp. 213-232, 1980, doi: 10.1080/00207548008919662.

[13] S. J. Yang, D. L. Yang, and T. R. Chang, "Single-machine scheduling with joint deterioration and learning effects under group technology and group availability assumptions," J. Chinese Inst. Ind. Eng., vol. 28, no. 8, pp. 597-605, 2011, doi: 10.1080/10170669.2011.648214.

[14] S. Y. Lee and T. C. Chen, "Using evolutionary computation approach to improve the performance of the fuzzy-art for grouping parts," J. Chinese Inst. Ind. Eng., vol. 18, no. 5, pp. 55-62, 2001, doi: 10.1080/10170660109509505.

[15] F. Alhourani and H. Seifoddini, "Machine cell formation for production management in cellular manufacturing systems," Int. J. Prod. Res., vol. 45, no. 4, pp. 913-934, 2007, doi: 10.1080/00207540600664144.

[16] M. P. Chandrasekharan and R. Rajagopalan, "Modroc: An extension of rank order clustering for group technology," Int. J. Prod. Res., vol. 24, no. 5, pp. 1221-1233, 1986, doi: 10.1080/00207548608919798.

[17] R. Ernst and M. A. Cohen, "Operations related groups (ORGs): A clustering procedure for production/inventory systems, ” J. Oper. Manag., vol. 9, no. 4, pp. 574-598, 1990, doi: 10.1016/02726963(90)90010-B.

[18] Y. T. Abdul-Hamid, A. K. Kochhar, and M. K. Khan, "An analytic hierarchy process approach to the choice of manufacturing plant layout," Proc. Inst. Mech. Eng. Part B J. Eng. Manuf., vol. 213, no. 4, pp. 397-406, 1999, doi: 10.1243/0954405991516868.

[19] R. Ramanathan, "ABC inventory classification with multiple-criteria using weighted linear optimization," Comput. Oper. Res., vol. 33, no. 3, pp. 695-700, 2006, doi: 10.1016/j.cor.2004.07.014.

[20] A. Bhattacharya, B. Sarkar, and S. K. Mukherjee, "Distance-based consensus method for ABC analysis," Int. J. Prod. Res., vol. 45, no. 15, pp. 3405-3420, 2007, doi: 10.1080/00207540600847145.

[21] K. Šimunović, T. Draganjac, and G. Šimunović, "Application of different quantitative techniques to inventory classification," Teh. Vjesn., vol. 15, no. 4, pp. 41-47, 2008. 
[22] H. Kaabi and K. Jabeur, "TOPSIS using a mixed subjective-objective criteria weights for ABC inventory classification," Int. Conf. Intell. Syst. Des. Appl. ISDA, vol. 2016-June, no. November 2016, pp. 473-478, 2016, doi: 10.1109/ISDA.2015.7489161.

[23] K. R. Žalik, “An efficient k'-means clustering algorithm,” Pattern Recognit. Lett., vol. 29, no. 9, pp. 1385-1391, 2008, doi: 10.1016/j.patrec.2008.02.014.

[24] W. L. Ng, “A simple classifier for multiple criteria ABC analysis,” Eur. J. Oper. Res., vol. 177, no. 1, pp. 344-353, 2007, doi: 10.1016/j.ejor.2005.11.018.

[25] P. Trebuňa and J. Halčinová, "Mathematical Tools of Cluster Analysis," Appl. Math., vol. 04, no. 05, pp. 814-816, 2013, doi: 10.4236/am.2013.45111.

[26] T. Šarić, K. Šimunović, D. Pezer, and G. Šimunović, "Inventory classification using multi - criteria abc analysis, Neural networks and cluster analysis," Tech. Gaz., vol. 21, no. 5, pp. 1109-1115, 2014.

[27] M. K. Ghorabaee, E. K. Zavadskas, L. Olfat, and Z. Turskis, "Multi-Criteria Inventory Classification Using a New Method of Evaluation Based on Distance from Average Solution (EDAS)," Inform., vol. 26, no. 3, pp. 435-451, 2015, doi: 10.15388/Informatica.2015.57.

[28] A. M. L. Raja, T. J. Ai, and R. D. Astanti, "A Clustering Classification of Spare Parts for Improving Inventory Policies," IOP Conf. Ser. Mater. Sci. Eng., vol. 114, no. 1, 2016, doi: 10.1088/1757899X/114/1/012075.

[29] D. Pezer, "Efficiency of K-Means Algorithm and Various Hierarchical Efficiency of K-Means Algorithm and Various Hierarchical Clustering Methods in the Inventory Classification," no. July, 2017, doi: 10.13140/RG.2.2.32349.51685.

[30] E. Balugani, F. Lolli, R. Gamberini, B. Rimini, and A. Regattieri, "Clustering for inventory control systems, " IFAC-PapersOnLine, vol. 51, no. 11, pp. 1174-1179, 2018, doi: 10.1016/j.ifacol.2018.08.431. 